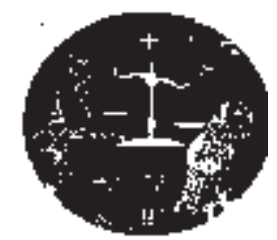

\title{
A história do Desenvolvimento do grafite URBano CONTEMPORÂNEO NOS EsTADOS UNIDOS DE 1965 A 1979
}

\author{
DOI: $10.12957 /$ synthesis.2014.19671
}

\section{William da Silva-E-SiLVA *}

\begin{abstract}
Resumo: Jovens, em sua maioria homens negros, criaram, fortaleceram e difundiram nos Estados Unidos o grafite contemporâneo, um tipo de intervenção urbana que teve como base o tag inscrito com a tinta acrílica da lata de spray. Em Nova York as intervenções urbanas contemporâneas atingiram primeiro o interior dos carros do metrô, depois o exterior dos mesmos, as estações, passaram para os trens, depois ônibus, caminhões e então paredes, postes e demais suportes públicos. Na década de 1970 houve uma explosão quantitativa deste fenômeno nos EUA, com um ápice no ano de 1972. Veremos neste artigo os principais sujeitos envolvidos neste processo e as diferentes contribuições que trouxeram para o desenvolvimento do grafite urbano como o uso do tag, a criação da masterpiece no ano de 1971, das letras bubble em 1973, das letras neo-bubble e do wild style em 1974, este último um estilo novo de letra em ângulos oblíquos. Em 1977, Tracy e Blade iriam continuar a desconstruir letras no wild style desenvolvendo a letra 3D, criando para o grafite a perspectiva em três dimensões.
\end{abstract}

Palavras-chave: Grafite Urbano Contemporâneo. Grafiteiro. Cidade. Nova York.

\section{The development of the history of contemporary urban graffiti in the United States from 1965 to 1979}

Young, mostly black men, created, strengthened and spread in the United States the contemporary urban graffiti, a type of urban intervention that was based on the tag inscribed with acrylic paint spray can. In New York contemporary urban interventions first reached the inside of subway cars, then the outside itself, the seasons, went to the trains, then to buses, trucks and then the walls, poles and other public supports. In the 1970s there was a quantitative explosion of this phenomenon in the US, with a peak in 1972. We will see in this article the main subjects involved in this process and the different contributions that have brought to the urban graffiti's development as the use of the tag, the creation of the masterpiece in 1971, to the bubble letters in 1973, to the neo-bubble letters and Wild style in 1974, the latter a font new style at oblique angles. In 1977 Tracy and Blade would continue to deconstruct the letters in wild style developing 3D letter, creating the prospect for graphite in three dimensions.

Keywords: Contemporary Urban Graffiti. Graffiti. City. New York.

\footnotetext{
* Doutor em História Social pela Universidade Federal Fluminense. williamdasilvaesilva@ig.com.br
}

\section{INTRODUÇÃO}

Uma vez que entre os conceitos encontrados (como o subway graffiti, por exemplo) não há sequer um a contemplar integralmente nosso objeto de estudo, resolvemos concatenar o que vem a ser grafite urbano contemporâneo. Dentre os especialistas do 
tema escolhemos as melhores definições, de pesquisadores distintos, as mais perspicazes em determinado aspecto. A nosso ver são complementares e apresentadas reunidas como foi fornecem uma definição senão completa, ao menos abrangente, que responde bem ao enquadramento do objeto: “[...] grafite consiste em assinaturas, codinomes, depois seguidos por nome de gangue." (LEY; CYBRIWSKY, 1974, p. 496).

[Tratava-se de uma] "nova forma popular, de pintura de pulverização". (Ibid). Para o historiador Paulo Knauss trata-se de "[...] inscrições urbanas baseadas na aplicação do jato de tinta sobre paredes sem tratamento de suporte". (KNAUSS, 2001, p. 342). Para o sociólogo francês Jean Baudrillard os grafites são como pseudônimos lançados contra o sistema, "uma matrícula simbólica, feita para derrotar o sistema comum de nomeação". Por outro lado, são também reivindicação de identidade pessoal e de grupo. Já o antropólogo argentino Néstor García Canclini manifesta em seu livro Consumidores $e$ cidadãos que o "grafite é [...] para as tribos urbanas da Cidade do México, para grupos equivalentes de Buenos Aires ou Caracas, uma escritura territorial da cidade, destinada a afirmar a presença e até a posse sobre um bairro." Em outro trabalho, chegamos a definir o grafite como uma arte gráfica, uma comunicação visual que faz circular mensagens através de símbolos e letras elaborados a partir de um repertório simbólico que, segundo a vontade do sujeito, tanto pode ser comum à sociedade, como restrita a pequenos grupos de sujeitos. ${ }^{1}$ É uma linguagem indissociável de seu suporte (público) urbano, caracterizando-se por interferir diretamente sobre paredes ou muros com pinturas ou escritos. Um grafite pode ou não ser lúdico. (Ibid., p. 52-53).

\section{INICIO dO MOVIMENTO dO GRAFITE NOS EsTADOS UNIDOS}

Jovens, majoritariamente homens negros, residentes em solo norte-americano, fizeram dos Estados Unidos o berço do grafite urbano contemporâneo. Eles foram os principais responsáveis pelo seu fortalecimento e difusão. Marcos históricos neste processo são as intervenções da Philadelphia (1965-1970); e a "explosão" de grafites no metrô de Nova York (década de 1970).

Provocando motivações em abundância, em muitos adolescentes, o grafite se propagou no cenário internacional a partir de ações de jovens indivíduos residentes em solo norte-americano. ${ }^{2}$ Em uma das versões sobre a origem do grafite urbano contemporâneo, o início da prática deste fenômeno moderno, caracterizado pelo uso da lata spray, foi em meados da década de 1960 na Philadelphia, logo depois irradiando-se para localidades vizinhas. Todavia, sua propagação irrefreada pelas cidades do mundo teve como epicentro Nova York, mais fortemente os bairros Manhattan, Bronx e Brooklyn, bairros marcados por forte presença de grafite urbano desde os primeiros anos, e a lata spray foi uma das responsáveis por isso. ${ }^{3}$

A publicação por David Ley e Roman Cybriwsky, de Urban graffiti as territorial markers (LEY; CYBRIWSKY, 1974, p. 491-505) ${ }^{4}$, foi resultado de uma pesquisa muito bem sucedida no campo da geografia humana sobre grupos de grafiteiros que agiam na Philadelphia, segundo os autores, desde 1965. Este artigo foi crucial como fonte de referência de época porque nos fornece dados para incorporarmos a cidade de Philadelphia como origem do circuito desta expressão cultural contemporânea. Segundo os autores, "o reaparecimento contemporâneo do grafite data de 1965. [...] O rápido aumento em 1972 acompanhado de uma "epidemia urbana" nas cidades da Costa Leste [tratava-se de uma] nova forma popular de pintura de pulverização". (Ibid., p. 491, tradução nossa).

Posicionar Philadelphia como berço do grafite moderno e não a cidade de Nova York é ir contra uma tendência dominante, assim como introduzir a periodicidade de 1965 como um dos marcos temporais iniciais deste movimento cultural. ${ }^{5}$

Vamos nos apropriar do artigo dos geógrafos como uma fonte de época, produzida em 1974 (no auge do fenômeno), e do livro de Jack Stewart, de 2009 (mas 
que interroga eventos do início da década de 1970 em Nova York), no que concerne ao preenchimento de uma lacuna de alguns anos na historiografia do grafite contemporâneo. ${ }^{6}$

Dois nomes ligados a esta cena, citados no artigo Urban graffiti as territorial markers e também por Jack, como os primeiros sujeitos do movimento do grafite contemporâneo, são os jovens Cool Earl e Cornbread. Ninguém no interior do movimento do grafite questiona a versão de origem do grafite urbano contemporâneo que apresenta Cornbread como o primeiro grafiteiro moderno. Não há contestação recente, não houve na década de 1960 ou 1970. Ao contrário, outros jornalistas e pesquisadores apoiaram Philadelphia como o local inicial.

Dois artigos jornalísticos bem posteriores às abordagens de Ley, Cybriwsky e Stewart irão corroborar esta versão de origem, que ressaltamos não ser a única existente. Em 2010, o jornal Philadelphia Citypaper também creditou ao grafiteiro a origem da escrita parietal contemporânea: "Cornbread é o pai da moderna escrita grafite. [...] É uma cultura que começou [na Philadelphia] e se afastou, lamenta Cornbread. Quando eu fui para Nova York, fui bem recebido, muito amado. Não consegui isso aqui na Philadelphia." (CURRIER, 2010).

Em 2011, o The New York Times faz referência a Cornbread e Julio 204, respectivamente, da Philadelphia e Nova York, considerando-os artistas e atribuindo-lhes notoriedade nos anos 60 e 70 . (GREENBAUM; RUBINSTEIN, 2011).

A instituição Dreweatts, responsável por uma exposição aberta a leilão em 2011, contando com a participação de Darryl McCray e sua obra, afirma que "ele começou a escrever a sua tag "Cornbread" [...] em 1967." (DREWEATTS Catalogue, 2011, p. 22).

Cornbread é considerado como um dos (se não o) primeiro verdadeiro escritor de grafite. Em uma entrevista com David Cano, Cornbread falou sobre como ele se tornou o primeiro artista moderno de grafite:
- Eu realmente atingi o centro das atenções quando um rumor foi publicado sobre mim sendo morto com tiros na cara em 1971. Quem realmente morreu foi um amigo meu, Cornelius [...] as pessoas se aglomeraram ao redor gritando “Corn foi baleado, milho está morto!" Quando a imprensa chegou ao local, ouviram isso e pensaram que era eu. Depois eu soube que tinha que fazer algo bizarro ou o meu nome seria enterrado com o garoto. Foi quando invadi o zoológico de Philadelphia e pintei com spray "Cornbread Vive" em um elefante. (Ibid., p. 22).

Assim, “[...] no aeroporto, Cornbread pulverizou um jato da empresa aérea TWA que levou para o sul seu nome em cima de suas asas. Podia-se ler no aeroporto "Cornbread recebe você na Philadelphia".” (STEWART, 2009, p. 493, tradução nossa). Outros codinomes que eram fortemente ativos, repetidamente assinados, no espaço urbano desta época, segundo o texto Urban graffiti as territorial markers, eram Cool n ${ }^{\circ}$, Cool Earl, Bobby Cool, Koool Kev e Sir Smooth.

Um grupo de escritores nova-iorquinos afirmou

[...] ter inventado a seta ${ }^{7}$, entre eles a Phase 2, Stayhigh 149 e Tracy 168. Mas, na verdade, Cool Earl tinha usado na Philadelphia já em 1966. (Ibid., p. 58). [Veja a Figura 1, neste artigo.]

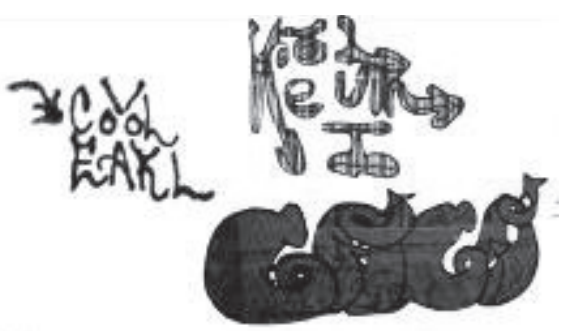

Figura 1 - Primeiras setas na Philadelphia Fonte: STEWART, 2009, p. 59.

Em 1965, Cornbread, então com 11 anos de idade, foi enviado para um reformatório, onde ele pegou seu apelido. (Ele implorou ao cozinheiro da instituição para servir cornbread [- broa de milho -] como sua avó costumava 
fazer). Durante esse tempo, as pessoas estavam compreensivelmente cautelosas com o grafite, que era tipicamente usado para designar territórios de gangues. Cornbread encontrou uma maneira de contornar a forma violenta de convivência intragangues: - Os membros das gangues costumavam vir para mim, porque era um escritor poético. E eu costumava escrever cartas de amor poéticas para as namoradas deles... E quando saí [do reformatório], eu fiz o meu negócio para ir visitar cada gangue que conheci quando estava no [reformatório], fui beber vinho com eles. E esse foi o meu passe para me locomover pela cidade sem apanhar. (CURRIER, 2010).

Com a liberdade para se movimentar entre os territórios de gangues, Cornbread deixou a sua marca ao longo de bairros inteiros. "Quanto mais [as pessoas] falavam de mim", diz ele, admitindo o canto da sereia da celebridade, "mais eu escrevia.”Ao contrário dos membros de gangues ou ativistas políticos, Cornbread simplesmente queria chamar atenção. (Ibid).

Desfiguração de tinta spray no sistema de metrô está custando à Autoridade de Trânsito 1 milhão de dólares por ano. [...] A Time estima que a Philadelphia tenha mais ou menos 10 mil artistas grafiteiros habitualmente, em 1974. (Time, March 13, 1972, p.44; LEY; CYBRIWSKY, 1974, p. 492).

Cornbread parou de escrever em 1972; depois de muitos anos longe "da cena" ele começou a pintar novamente. (DREWEATTS Catalogue, 2011, p. 22).

Consta que Darryl McCray (Cornbread) nasceu e foi criado em Brewerytown, EUA. E em tempos recentes se tornou "um mentor de jovens que dá aulas em universidades locais, como a Drexel e Templo." (CURRIER, 2010).

Em 2007, foi lançado o documentário Grito; a primeira parte foi nomeada City 1: A Lenda de Cornbread. (Ibid).

Um meio de comunicação de massa acessível a qualquer um estava ganhando grande visibilidade. "[...] grafite consiste em assinaturas, codinomes, depois seguidos por nome de gangue." (Ibid., p. 496).

Não chamávamos isso de grafite. Dizíamos: "Vamos escrever alguma coisa esta noite". Grafite foi um termo inventado pelo "New York Times" para denegrir a nossa arte, porque ela foi inventada por jovens de cor, diz Mico, um dos que já empunhavam o spray no fim dos anos 60 . (CELESTINO, 2006).

\section{A EXPANSÃO dO MOVIMENTO dO GRAFITE}

O ano de 1967 foi importante na história da arte urbana. Na Inglaterra John Upton foi preso pela polícia por ter sido o responsável pela elaboração de um painel mural. "Sua repercussão originou outras iniciativas que se seguiram dando origem ao movimento de pintura mural comunitária no Reino Unido." (KNAUSS, 2001, p. 334). O historiador, professor da Universidade Federal Fluminense, no Rio de Janeiro, e pesquisador de arte pública, Paulo Knauss, explicita que no mesmo ano, nos Estados Unidos, a luta pelos direitos humanos obteve destaque, ganhou as ruas com pinturas murais políticas.

No ano seguinte, em maio de 1968, a inscrição livre também foi usada na França como veículo de comunicação que forneceu voz aos gritos de recusas e expectativas dos interventores urbanos, fenômeno que contou com forte participação popular, serviu para registrar na cidade o descontentamento para com o contexto social e político da época. Um dispositivo simbólico que naquele momento histórico foi manipulado pela massa popular constituída, majoritariamente, por estudantes e trabalhadores revoltados e revoltosos. Gitahy (1999, p. 21) diz no livro O que é graffiti?: "Durante a revolta dos estudantes iniciada em maio de 1968 em Paris, vimos como o spray viabilizou que as mesmas reivindicações que eram gritadas nas ruas fossem rapidamente registradas nos muros da cidade".

Para Cristina Fonseca, autora do livro A poesia do acaso na transversal da cidade, publicado em 
1982, os grafites franceses de Maio de 68 se restringiram basicamente aos muros e arredores da Sorbonne. Foram revolucionários, inclusive influenciaram as inscrições nova-iorquinas e brasileiras. Sabemos que o movimento foi sustentado por estudantes e, sendo assim, foram as representações desses jovens a impregnar os muros e a mídia. Representações estas transferidas para a mesma classe, em outros lugares do mundo, numa disseminação global. A divulgação desses acontecimentos deu-se em jornais de vários países, inclusive com relatos de protestos escritos nos muros das cidades. A mídia impressa possibilitou o contato desse tipo de intervenção urbana com múltiplas culturas, incluindo as do território sul-americano.

O movimento parisiense se destacou pela grande diversidade da produção de protestos registrados visualmente, onde houve uso abusivo de cartazes (serigrafias tipo silkscreen) e só no processo é que outras expressões foram aparecendo, incluindo as inscrições feitas a mão livre com lata de tinta spray. Vale ressaltar que no Maio de 68 havia muita tinta de gente motivada por inspiração ideológica baseada em grupos organizados e partidários, destacando-se tendências maoístas, pessoas que conheciam os filmes de Godard, além de formação artística acadêmica, distinguindo o produto da criação parisiense das ruas das cidades da costa leste dos Estados Unidos. A lata de tinta spray fez a diferença nesse contexto e uniu manifestações de natureza distinta.

De todo modo, o grafite acompanhou a afirmação do poder jovem. O poder jovem da França foi, nesse momento, o poder dos estudantes universitários engajados ideologicamente. Enquanto no outro lado do Atlântico, em Nova York, há outro perfil, o jovem que não era integrado plenamente na ordem social e não participava de organizações orientadas ideologicamente ou partidariamente. Sobretudo, havia o jovem que não era do movimento estudantil, não era de qualquer partido comunista, em muitos casos não pertencia a uma família e nem ia à escola. Por vezes é desvinculado de instituições (isso faz com que a gente não saiba como ele se reproduz), mas ele se reproduz, ele se aproveita de todos os subterrâneos para se reproduzir: usa o subterrâneo das gangues, das crews, de diferentes "tribos urbanas" estabelecidas nos bairros.

Em 1968, o então candidato ao cargo de presidente norte-americano, Richard Nixon, atento a estas e outras manifestações populares assumiu uma atitude em favor da igualdade racial. ${ }^{8} \mathrm{E}$ no ano seguinte, já como presidente eleito multiplicou por três a verba orçamentária destinada às artes.

Em depoimento, o grafiteiro Chaz, ao contar o início de sua história como interventor parietal, destaca como no verão de 1969 “jovens começaram a escrever seus nomes nas paredes de Washington. O número aumentou no verão seguinte, com tags espalhados a partir da ponta norte de Manhattan ao longo das rotas de transporte de massa para o Bronx e Brooklin." (STEWART, 2009 , p. 26). Para este mesmo ano de 1969, Jack Stewart contabiliza a atuação dos sujeitos: Julio 204, Taki 183, Greg, Caesar, Broson, Phil. T. Greek, SJK 171, Che 159, Cay 161, Cay 161, Baby Face 86, Rican 619, Rogue 1, Jesus 137, Franky 135; Dutch 135, Rat I; Chew 127, Tree 127; Ralph 611; FJC IV; RLM II; Cliff 159; Frank 207; Cloud 160; Ace 137; CAT 87, e El Marko 174. (Ibid., p. 25). Segundo Nicholas Ganz, nos Estados Unidos da América, no fim da década de 1960, atuavam os grafiteiros Cap One, Chris Silva (um portoriquenho atuante em Chicago) e Stayhigh 149, um dos pioneiros em Nova York, que pinta desde 1969, aproximadamente, e continua ativo. (GANZ, 2008, p. 107).

Em Nova York, as intervenções urbanas contemporâneas atingiram os veículos de transporte de massa. $\mathrm{O}$ grafite conquistou primeiro o interior dos carros do metrô (Ibid., p. 43. Tradução nossa), depois, o exterior dos mesmos, as estações, passou para os trens, depois ônibus, caminhões e então paredes, postes e demais suportes públicos. A entrada na década de 1970 coincidiu com a explosão quantitativa do grafite urbano contemporâneo nos EUA, que teve o ápice no ano 
de 1972.

Nessa altura, o grafite urbano contemporâneo começa a se afirmar como um fato jornalístico no The New York Times (1971), em seguida se torna um fato de interrogação intelectual. Neste campo, ao considerarmos as obras de repercussão internacional, temos o livro do ganhador de dois prêmios Pulitzer (em 1969 e 1980) Norman Miler, intitulado The faith of graffiti, publicado originalmente em 1974, em Nova York, por Praeger/Alskog. O artigo Kool Killer ou Insurreição dos Signos (1976) se tornou a primeira abordagem ensaística, publicada originalmente em livro, na França, pela Gallimard Editora. E finalmente surgiu uma abordagem mais sistemática de pesquisa com a publicação de Getting up. Subway graffiti in New York, escrito por Craig Castleman, no ano de 1982.

Há uma construção discursiva depois da imprensa. Castleman dá voz ao grafiteiro. Dentre as entrevistas contidas em seu livro consta uma com o grafiteiro Lee do grupo Fabulous Five, em que Lee relata a Castleman como foi sua experiência de grafitar pela vez um trem inteiro, dez vagões. Numa noite, Lee teve a ideia e a comunicou ao grupo, demais membros do Fabulous Five, Mono e Slave, que aderiram, os demais eram novatos demais para a ação. Os três se encarregaram da empreitada. Por alguns dias planejaram os desenhos no papel dimensionando todo o espaço externo, a referida quantidade de desenho para cada um dos dez vagões. Calcularam que seriam necessárias cento e dez latas de spray, pelo menos. Somente Slave possuía sua quota de spray, Lee e Mono tiveram que investir dias para adquirir o restante. Tudo pronto!... Se reuniram numa noite, às $21 \mathrm{~h}$, com comida na bagagem partiram em direção à estação. Ao chegarem ao trem, vazio e estacionado, os três entraram no primeiro vagão, lá organizaram as latas correspondentes a cada vagão e imediatamente distribuíram as porções pelos outros vagões, os jogos de cores correspondentes ao "projeto" colocados em um dos bancos de cada carro. Segundo Lee, ele construiu todo o primeiro vagão em menos de uma hora. Um vagão levou a inscrição "Fabulous Five" e um desenho do Mickey Mouse; outro vagão teve exposto o nome de Lee. No meio da elaboração tiveram que correr da polícia. Fugiram, se reuniram na cidade, mas ao invés de desistir resolveram voltar e terminar o que começaram. Neste acontecimento estão representados o tag (nome de Lee), a influência da indústria cultural - na figura do Mickey Mouse e a exaltação da identidade coletiva da crew Fabulous Five.

Castleman inicia seu livro direcionando sua abordagem para o fim de 1960, com relatos minuciosos sobre os grafites das estações de metrô e dos interiores e exteriores dos vagões novaiorquinos. ${ }^{9}$ Especifica que os tipos de traços mais utilizados eram o fino, de única cor para retratar muitos nomes e apelidos. Põem sob a ótica da análise a forma da manifestação: o tamanho, a complexidade do desenho, os materiais utilizados. Realizou algumas entrevistas, treze páginas só com depoimentos do grafiteiro Lee do grupo Fabulous Five. Na segunda metade do livro aparecem nomes de interventores dos bairros do Bronx e Brooklin.

Segundo o historiador da arte, professor e pintor Jack Stewart, no início da década de 1970 surgem em Nova York, os sujeitos Kool Wiff, King Kool 163, Super Kool 223, Soul e Tracy 168. Stewart os chamará de segunda geração de escritores. O pesquisador correlacionou gerações às décadas. Somam-se a esta lista Taki 183, Angel 136, Yanqui 135, Junior 161, Rat I, Cay 161, Joe 82, Tony 184. Do Bronx: Pearl 74, Sexy 62, Cartoon 62 e Cowboy 60. Clyde foi intitulado "king of the Buses". "Bama I atestou a fama de Clayde: Clayde foi o primeiro a fazer bomber em ônibus." (STEWART, 2009, p. 23. Tradução nossa). Entre os jovens que resolveram atuar sobre os ônibus estavam: o CAT 87, o Spade 130, o Snake I, o Stitich I. E "Bárbara 62 e Eva 62 foram as primeiras [...] garotas a escrever grafites no metrô de Nova York." (Ibid., p. 49). Neste mesmo período, início da década, Stayhigh 149 lançou seu tag "sobre o 
velho carro vermelho do metrô, número 8985". (Ibid., p. 48).

Nancy Beaulieu no texto Sauvez mon art! entende tag como "[...] uma espécie de assinatura pessoal que alguns grafiteiros afixam nas paredes tão frequentemente quanto possível." (BEAULIEU, 2002, p. 2). Paulo Knauss é mais específico, para ele o tag é logomarca, e

[...] constitui a base de todo o desenvolvimento formal que evolui das soluções alfanuméricas iniciais para soluções logotípicas das letras emboladas, quase criptogramas, por vezes, adornadas com detalhes figurativos complementares ou pela tridimensionalidade. (KNAUSS, 2001, p. 335).

Segundo depoimento dado pelo grafiteiro Ota: "Tem que ter um símbolo, um logotipo que o pessoal olhe e veja: esse é o Ota, esse é o Lucas. Assinatura é a valorização da autoestima." (BEDOIAN; MENEZES, 2008, p. 40). Nicholas Ganz, por sua vez, considera tags como sendo as assinaturas chamativas do grafiteiro, que " $[$...] se tornaram cada vez maiores até aparecerem as primeiras pieces nos trens de Nova York". (GANZ, 2008, p. 9).

Vale frisar aqui que o grafite urbano contemporâneo "nasceu" a partir do tag.

Os pesquisadores David Ley e Roman Cybriwsky construíram mapas da geografia urbana da cidade de Philadelphia apontando onde cada gangue grafitava entre (1970-1972), a quadra exata de cada domínio territorial, como mostra a Figura 2. Cybriwsky afirmará que o gueto norte da Philadelphia era uma área residencial constituída de uma vizinhança negra, porto-riquenha, com grande presença de jovens recém-imigrados de Porto Rico. Estes mapas constituem documento de uma relevância à parte, porque os dados que fornecem nos permitem preencher na historiografia do grafite contemporâneo uma lacuna temática e outra espacial nesse nicho - através da aglutinação das relações entre gangues e a prática do grafite.

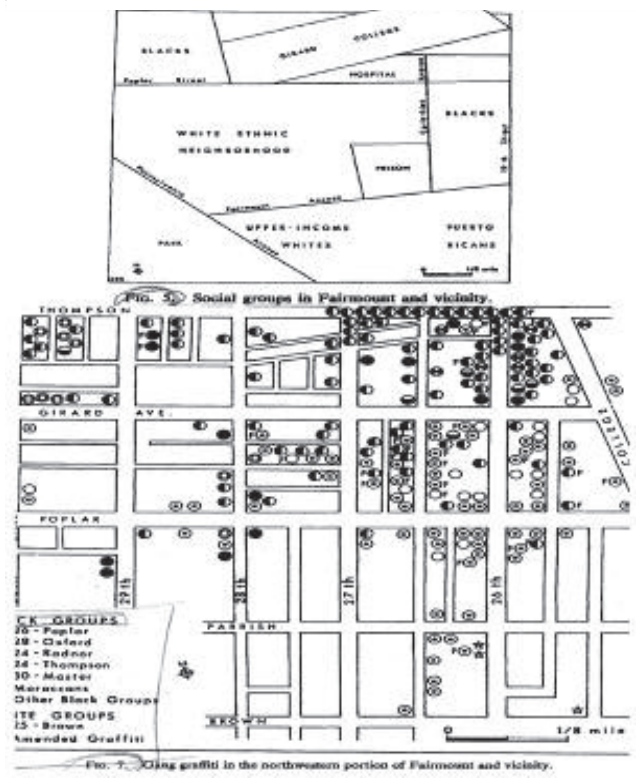

Figura 2 - Mapa de Philadelphia

Fonte: LEY; CYBRIWSKY, 1974, p. 497

O livro de Jack Stewart, Graffiti kings. New York city mass transit art of the 1970s, é uma importantíssima fonte, publicado em 1989, como resultado de pesquisa para a obtenção de doutorado em história da arte, enfatizava os primeiros anos do grafite urbano contemporâneo. Jack Stewart viveu em Nova York no momento do boom do grafite. O livro Graffiti kings usa como fontes o artigo do jornalista Don Hogan Charles 'Taki 183'spawns pen pals (The New York Times. July 21, 1971, p. 37); e o excelente artigo dos geógrafos David Ley e Roman Cybriwsky. O enfoque comporta os sujeitos de criação, seus locais de intervenção (geografia), as respectivas assinaturas, motivações. Em seu trabalho, Jack Stewart destaca uma das marcas do grafite urbano contemporâneo em Nova York, a criação das masterpieces, inscrições em grande escala. Segundo o autor, no ano de 1971, El Marko 174 pode ter sido o primeiro a realizar uma masterpiece. (STEWART, 2009, p. 62). Veja a Figura 3. Segundo Stewart, este tipo de criação se definia da seguinte forma: 

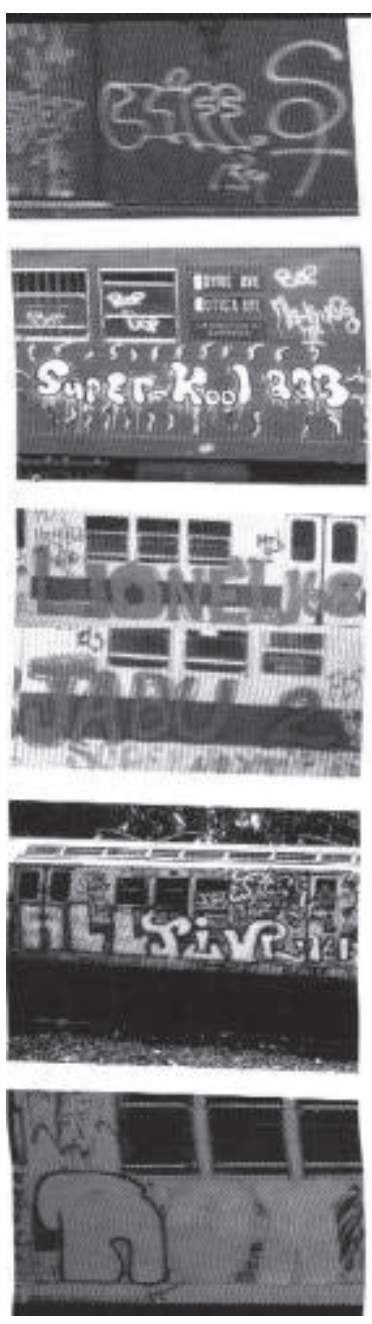

Figura 3 - As Masterpieces.

Fonte: STEWART, 2009, p. 62.

[...] Uma masterpiece tinha de contar com três qualidades: grande escala, outline letters [cartas esboço], e decoração dentro das outline letters. (Ibid.). Uma composição do velho metrô vermelho no verão de 1971 inicia carregada com tags de escritores incluindo Bop Bop Bop, Santana 204, King Kool 143, Solid, Bachelor Jin One, e Tracy 168. (Ibid., p. 54). Muitos dos escritores adquiriam, de uma forma ou de outra, conjuntos de chaves de condutores, dando-lhes acesso a todos os carros. (Ibid., p. 52).

Assim, por meio da criação de masterpieces os trens urbanos foram transformados em vitrines da expressão cultural. O observador parado passou a ver o tag em movimento, em consequência disso surgiu a necessidade de elaborar em tamanhos maiores e combinar com desenhos. A partir daí as grandes inscrições passaram a ser usadas para expor os codinomes assumindo proeminência e dos trens contagiavam também os muros das cidades.

O primeiro grupo organizado que reuniu grafiteiros foi a UGA - United Graffiti Artists, a primeira $\mathrm{Crew}^{10}$ fundada oficialmente em 1972 pelo sociólogo Hugo Martinez, Snake Li, Stich I, CAT 87, Lee 163, Flint 707, Mico, Phase II, Wilked, Gary, Sjk 171, T-Rex 131, Co-Co e Bama. (KNAUSS, 2001, p. 338). A partir da fundação da UGA a preocupação com a estética passa a ser incluída em outra dimensão, passa a ter uma maior importância junto com o aprimoramento técnico: o uso do brilho, da luz e sombra, uso de mais cores, traços firmes etc. A partir deste contexto começam a se reforçar laços entre grafiteiros, constituindo grupos que condicionavam a criação individual.

Em 1974, sob a liderança do ator e bailarino Jack Pelsinger, surge outra associação importante, denominada NOGA - Nation of Grafitti Artists." (Ibid., p. 338).

O primeiro artigo jornalístico a utilizar o termo grafite para expor o fenômeno cultural pesquisado aqui tinha por título 'Taki 183' spawns pen pals. É um artigo informativo e imparcial. Escrito pelo jornalista Don Hogan Charles, foi publicado em 21 de julho de 1971 no jornal The New York Times. O texto confere notoriedade nacional e internacional ao “Taki 183” por colocá-lo na posição de primeiro grafiteiro a receber destaque na imprensa escrita.

Quem foi Taki? Em entrevista concedida ao jornalista, o grafiteiro de dezessete anos declarou que o codinome Taki é diminutivo em grego de Demétrius, primeiro nome do jovem que nesta época vivia em Manhattan, na rua 183. Um jovem de origem grega, que desde o fim da década de 1969 tinha por hábito espalhar por quarteirões da cidade de Nova York seu codinome Taki, seguido pelo número de sua rua, formando Taki 183.

"Taki 183" é um marco na história do grafite porque é tido por muitos pesquisadores e artistas como o primeiro criador do grafite contemporâneo, o que é 
amplamente divulgado pela bibliografia específica. Contudo, não é verdade! Taki foi tão somente o primeiro a ser evidenciado e comentado extensamente pela imprensa da cidade de Nova York, principalmente no The New York Times. São coisas bem diferentes. Isto pode ser dito a partir de análise do próprio artigo de Don Hogan Charles. Primeiramente, no mesmo texto onde "Taki 183" é tratado, outros grafiteiros são mencionados, não só pelo jornalista, mas pelo próprio Taki. São listados contemporâneos do Demétrius, seguidores dele, tal como um antecessor que o inspirou: Júlio 204. Depoimento do próprio Taki: "Eu tomei a forma de Julio 204". (CHARLES, 1971, p. 37, tradução nossa). Em segundo lugar, a proporção do artigo evidencia uma distribuição entre problemas distintos: o texto é constituído de vinte e sete parágrafos, dos quais quatorze remetem à pessoa de Taki ou seus feitos (50\% mais 1: foi eleito pela maioria dos votos), os outros treze parágrafos (metade da atenção do jornalista) dividem-se entre outros interventores urbanos, outros grafites e a luta da Autoridade de Transporte Metropolitano para limpar a cidade. Em terceiro lugar, o artigo, apesar do título, não é sobre "Taki 183" e sim sobre o grafite da cidade de Nova York, dentre outras coisas, sua proliferação e os esforços das autoridades em combatê-lo. O texto de Stewart fala também dos gastos governamentais com a limpeza das pichações - política antigrafite desde a década de 1970. Mas a partir da publicação do artigo no jornal foi Taki 183 que ganhou uma notoriedade excepcional.

O sujeito agia nas estações do metrô e nas laterais dos trens " $[. .$.$] no caminho ao longo da Broadway,$ no Aeroporto Internacional Kennedy, em New Jersey, Connecticut, sobre Nova York e outro lugares" (Ibid.). As intervenções urbanas realizadas por Demétrius estimularam, segundo o repórter, o surgimento de vários imitadores, como "Joe 136, Bárbara 62, EEL 159, Yank 135 e Leo 136". Outras inscrições surgiram: Eva 62, Lady Pink, Zephir. Seguidas de Bana, Cay 161, Chew 127, Cool Here, Crash, Daze, Frank 207, Iron Mike, Junior 161, Kool Jeff, Lady Pink, NOC 167, Moetr, Sini, Sage, Snake 131, Tracy
168 e Wasp. Ele disse que "tinha adolescentes por todas as partes da cidade, de todas as raças e religiões e todas as classe econômicas [praticando grafites]." (Ibid., p. 37. Tradução nossa).

Com a promoção de "Taki 183" na imprensa, o número de adeptos do movimento do grafite urbano começa a aumentar massivamente, muitos outros somaram-se nesse momento aos ícones Cornbread, Cool Earl, Julio 204 e o próprio Taki 183 na ação de espalhar seus codinomes pela cidade, e com isso o visual da cidade sofreu modificações que incitaram a perseguição por parte das autoridades. Prisões eram feitas, penas alternativas eram aplicadas. AAutoridade de Trânsito estimou em 300 mil dólares ao ano o custo das remoções das pinturas. Segundo Craig Castleman, na obra Getting up. Subway graffiti in New York, já em 1971 o número de grafites era de tal proporção que a Autoridade de Transporte Metropolitano gastou cerca de 150 mil dólares para repintar a cidade, na tentativa de livrá-la dessa manifestação popular.

Consta que, em 1971, o carro 9044 do trem de metrô de Nova York foi pintado. No ano de 1973 os IRT carros das linhas A e CC foram pintados por Blade I; o carro 8873 do trem 5; o carro 7570 era o preferido de J 2 II e Dice 198; em 1973 Tracy 168 e RC-162 pintaram o 5845. (STEWART, 2009, p. 100. Tradução nossa). O carro 6263 ficou repleto de 3D feitos por Butch 2 em 1974, ano que Pugh, Phil e LSD também atuavam, este foi o período onde "Blade I foi o primeiro que pintou sozinho um carro de metrô inteiro, o que o credenciou como um dos maiores artistas de grafite. Usando linhas quase idênticas, ele pintou duas caricaturas de mulheres." (Ibid., p. 163). Também foram incluídos na linha do spray os carros 9026 e 7777, ambos de 1978. Então, Moses 147 teria anunciado que "era o rei da linha número I com a M*147", concorrendo com Snake 131 considerado o primeiro rei da linha, autor de um número extraordinário de peças. (Ibid., p. 105).

Durante o verão de 1973, uma nova forma de letra foi produzida por Super Kool 223: as letras bubble (Ibid., p. 112) $)^{11}$ podem ser observadas na 
Figura 4. Neste mesmo ano, a Nova York Magazine “[...] tratou pela primeira vez na imprensa o grafite como uma nova forma de arte - contrapondo-se à posição das autoridades públicas." (KNAUSS, 2003, p. 338). De acordo com Jack Stewart, Taki parou com a sua criação por volta de 1973.

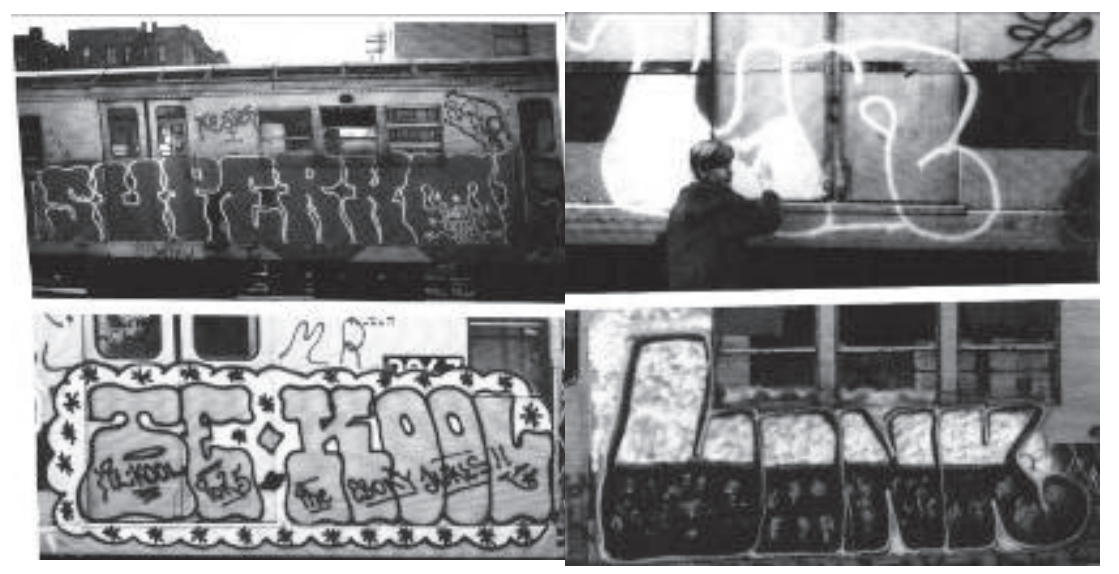

Figura 4 - As letras bubble

Fonte: STEWART, 2009, p. 112.

No ano seguinte, 1974, surgiram as letras neo-bubble "[...] dando uma sensação de circularidade pela adição de linhas curtas no interior.” (STEWART, 2009, p. 140). Ver Figura 5.

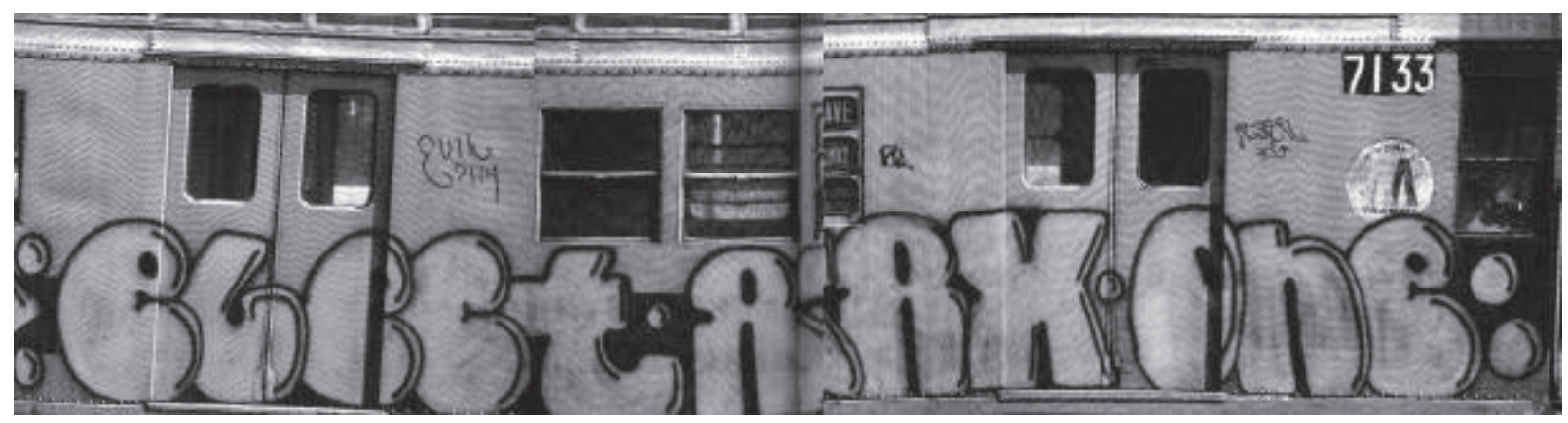

Figura 5 - As letras neo-bubble

Fonte: STEWART, 2009, p. 140.

Em 1974, Tracy 168 cunhou a expressão Wild style. “[...] A expressão rapidamente se tornou um termo genérico para um estilo novo de letra que contou com formas altamente fraturadas que pareciam saltar fora, em ângulos oblíquos." (Ibid., p. 116).

Jean Baudrillard ${ }^{12}$, no clássico texto Kool Killer, ou l'insurrection par les signes publicado em 1976, discutiu a cena do grafite em Nova York. Destaca dentre os primeiros atores sociais do movimento: "Duke, Sprit, Superkool, Koolkiller, Ace, Vipere, Spider, Eddie, Kola [...] Woodie110, Shadow 137” (BAUDRILLARD, 1976, p. 8).

Jovens negros porto-riquenhos são a origem do movimento. Os grafites são particulares a Nova York. (Ibid., p. 9). [A] insurreição invadiu a cidade como um lugar de reprodução e código [...] porque os sinais não jogam com a força, mas com a diferença. [...] Portanto, não há necessidade de massas organizadas, nem uma consciência política clara. (Ibid., p. 15-16). 
Para Baudrillard, os grafites são como pseudônimos lançados contra o sistema, "uma matrícula simbólica, feita para derrotar o sistema comum de nomeação". Por outro lado, são também reivindicação de identidade pessoal e de grupo.

[...] os grafites são o inverso de todos os signos midiáticos e publicitários. [...] Eles exportam o gueto para todas as artérias da cidade. (Ibid., p. 13). [...] como um antidiscurso, como a recusa de quaisquer elaborações sintáticas, poéticas, políticas, quanto menor elemento radical inexpugnável para organizar um discurso qualquer. Irredutíveis mesmo, por sua pobreza, eles resistem a qualquer interpretação, conotações, e não denotam nada nem pessoa alguma: nem denotação nem conotação, e assim escapam ao princípio de significado. (Ibid., p. 12).

Isto esclarece o significado político do grafite. [...] Sob o corte da repressão, a rebelião foi dividida em um organismo político marxista-leninista puro, duro e doutrinário de um lado e do outro neste processo cultural selvagem ao nível dos sinais, sem objetivo, sem ideologia, sem conteúdo. (Ibid., p. 15).

Nomes de forte presença em 1977 foram Mono, Doc, Lee, e Iz. Nessa época, Tracy e Blade iriam continuar a desconstruir letras no wild style, e alguns nomes cresceram indecifráveis para os de fora da arte, desenvolvendo a letra 3D. (STEWART, 2009, p. 116$).{ }^{13}$

Destaque para Nicholas Ganz como ícones do ativismo parietal da década de 1970, nos EUA, foram: Cattle, Dave Chino, Dalek. Daze grafita desde 1976, Dephect, Man One, Bask, Twist, Ninos Boom Box, Pose 2 e o neoexpressionista Dzine. A partir de 1979 iniciou o Been3. O que se pode afirmar é que até o final da década de 1970 as inscrições proliferaram-se intensamente.

\section{Considerações FINAIS}

Passado esse momento de euforia e expansão singular daqueles que manipulavam a expressão pública por meio do spray, o grafite experimentou uma nova fase, por volta da metade da década de 1970, caracterizada por sua entrada nas galerias de arte, o que significou a sua penetração na esfera das elites econômica e social, legitimando um espaço de afirmação social para o grafite urbano contemporâneo. Na pesquisa empreendida por Jack Stewart, a UGAUnited Graffiti Artists - invade o mundo das exposições abrindo o Razor Gallery em 4 de setembro de 1973. (STEWART, 2009, p. 87). Em seguida, em 1975, a UGA realiza "a primeira grande exposição em galeria de arte", no Artist'Space, de Nova York. (MOCA, 2012, grifo nosso).

Assim, o grafite urbano contemporâneo que tinha como base o tag inscrito com a tinta acrílica da lata de spray foi se afirmando como um fenômeno local em Nova York.

\section{NOTAS EXPLICATIVAS}

${ }^{1}$ William da Silva-e-Silva é historiador, pesquisador do presente artigo e autor do livro Graffitis em múltiplas facetas: definições e leituras iconográficas lançado pela Annablume em 2011.

${ }^{2}$ E qual o porquê desta prática? Quais são as motivações para criar grafites? As respostas encontradas estão no campo das subjetividades:

No livro Por trás dos muros: horizontes sociais do graffiti, de 2008, organizado por Graziela Bedoian, psicóloga, e por Kátia Menezes, jornalista e mestre em Comunicação e Semiótica, encontram-se algumas entrevistas realizadas com grafiteiros paulistas, por exemplo, Pastore e Ota. Os depoimentos destes interventores urbanos resumem, sob a autoridade dos agentes sociais, algumas funções do grafite urbano contemporâneo: demarcar território; socializar os artistas; e ressignificar o espaço da cidade.

"Mais do que os signos, propriamente ditos, interessa a relação, a ponte, a mediação, [o desafio,] a pressão do risco de ser apanhado pela polícia. [...] E a necessidade de sociabilidades alternativas." PAIS, José Machado \& BLASS, Leila Maria. Tribos Urbanas: produção artística e identidades. Lisboa: Imprensa de Ciências Sociais, 2004, p. 15.

${ }^{3}$ Trata-se de um marco na história da intervenção, isto porque possibilitou que intervenções fossem realizadas mais rapidamente, o que fez proliferar as ações.

${ }^{4}$ No momento da construção do artigo, David Ley, doutor em geografia, era professor-assistente lecionando na Universidade de Colúmbia Britânica, em Vancouver, Canadá. E Roman Cybriwsky, também doutor em geografia, professor assistente na Universidade Temple na Philadelphia.

${ }^{5}$ Historiografia já frágil, construída por diversos profissionais e a participação de uns raros historiadores. 
${ }^{6}$ Lacuna das mais significativas por ser referente ao surgimento do desenvolvimento do movimento do grafite.

${ }^{7} \mathrm{~A}$ inclusão de seta no tag, símbolo que aparece solto ou no final de uma letra, que tanto era feito em traço simples, como em contorno com preenchimento. Ibid., p. 58.

8 "Temos alcançado uma nova liberdade. Começamos a fazer a promessa real para o preto, bem como para o branco. [...] Nenhum homem pode ser totalmente livre enquanto o seu vizinho não é. Para avançar em tudo e ir em frente juntos. Isto significa preto e branco juntos, como uma nação, não duas. [...] O que resta é dar vida ao que está na lei: para garantir, finalmente, que como todos nascem iguais em dignidade diante de Deus, todos nascem iguais em dignidade perante o homem." NIXON, Richard. "Inaugural Address." January 20, 1969. The American Presidency Project. Disponível em: <http:// www.presidency.ucsb.edu/ws/?pid=1941>. Acesso em: 2 set. 2012. Tradução nossa.

${ }^{9}$ Los graffiti teve sua primeira versão em 1982 na língua inglesa.

${ }^{10}$ Crew é uma palavra que significa turma, em inglês, utilizada para designar grupos de grafiteiros que costumam pintar em conjunto.

${ }^{11}$ As letras bubble são letras cheias, de escrita volumosa.

${ }^{12}$ O sociólogo Jean Baudrillard nasceu em Reims, França, em 1929. Ele desenvolveu "[...] uma série de teorias que remetem ao estudo dos impactos da comunicação e das mídias na sociedade e na cultura contemporâneas." Enciclopédia Wikipedia. Jean Baudrillard. Vida. Disponível em: <http:// pt.wikipedia.org/wiki/Jean_Baudrillard>. Acesso em: $26 \mathrm{dez}$. 2012.

${ }^{13}$ Já para a revista Almanaque Grafite, na qual não encontramos referência à pichação, o exercício do grafite comportará estilos específicos denominados Throw-up, Wild, 3D e o Free Style. Vale a ressalva que a referida revista recebe a colaboração de grafiteiros.

Throw-up é um estilo mais fácil de realizar tecnicamente $\mathrm{e}$ mais barato, pois gasta menos material. Caracterizado pelo uso de poucas cores, não se pinta o fundo com muito contraste. Apresenta formas de letras e desenhos "cheios", dando um efeito de volume. Wild é o estilo mais criativo de grafite; traça nomes e formas difíceis de ler para quem não é grafiteiro, com cores e formas geométricas que lembram tatuagens tribais. O $3 D$ é o estilo mais realista, as formas parecem saltar do muro em nuances de luz e sombras, com cores altas e baixas. O grande diferencial, e o que definirá este estilo, é a perspectiva geométrica tridimensional, um efeito criado quando a altura e a largura que dominam o espaço de duas dimensões passam a se compor com a profundidade. Para a percepção de um espaço tridimensional acontecer faz-se necessário superar a percepção de bidimensional. Há grafites que conseguem apropriar-se de quatro dimensões espaciais: a altura, a largura, a profundidade e o tempo. Isto é feito quando transmitem a sensação de movimento além das dimensões anteriormente citadas. Por fim, o estilo Free Style totalmente livre mistura dois ou mais estilos ou pode ainda constituir qualquer tipo de desenho ou texto.

\section{REFERÊNCIAS BIBLIOGRÁFICAS}

ALMANAQUE DE GRAFFITI. São Paulo: Escala, n. 2, 2002.

AZEVEDO, A. L. Grafites revelam como amavam os romanos. O Globo, Rio de Janeiro, 04 maio 2003. Ciência e Vida, p. 48.

BAUDRILLARD, J. Kool Killer ou l'insurrection par les signes. In: L'échange symbolique et la mort. Paris: Gallimard, 1976, p. 118-128.

BEDOIAN, G.; MENEZES, K. (Org.). Por trás dos muros: horizontes sociais do graffiti. São Paulo: Peirópolis, 2008.

CALÓ, F. C. Questões etimológicas sobre os termos: grafite e pichação. In: FÓRUM DE PESQUISA CIENTÍFICA EM ARTES, 3., Escola de Música e Belas Artes do Paraná 2005. Curitiba, Anais... 2005.

CASTLEMAN, C. Los graffiti. Traducción: Pilar Vazquez. Madrid: Hermann Blume, 1987.

CHALFANT, H.; PRIGOFF, J. Spraycan art. London: Thames \& Hudson, 1987.

CHARLES, D. H. The New York Times. July 21, 1971, p. 37.

COOPER, M.; CHALFANT, H. Subway Art. London: Thames \& Hudson, 1984.

COSTA, D. Pichação carioca: etnografia e uma proposta de entendimento. Dissertação (Mestrado em Sociologia e Antropologia) - Universidade Federal do Rio de Janeiro, Rio de Janeiro: UFRJ, 2007.

COUTO, F. Grafites no planalto central. A Rede: Tecnologia para inclusão social. Ano 2, n. 16, julho 2006.

CURRIER, E. The writing on the wall: Graffiti pioneer Darryl McCray won't let himself get forgotten. Philadelphia City Paper, 2010. Disponível em: <http://archives.citypaper.net/ articles/2010/06/10/darryl-cornbread-mccray-graffiti>.

DICCIONARIO de la lengua española. Real Academia Española, Madrid. Disponível em: <http://buscon.rae.es/draeI/ SrvltConsulta?TIPO_BUS=3\&LEMA=calle $>$. Acesso em: 10 set. 2009.

DREWEATTS. Catalogue, Londres, 2011, p. 22.

ESQUENAZI, R. Rio antigo. Aventuras na história, Rio de Janeiro, fev. 2004. Disponível em: <historia.abril.com.br/ cotidiano/rio-antigo-433500.shtml >. Acesso em: 15 out. 2009.

FIGUEROA, F. El graffiti americano: del tikal maya a New York. Minotauro Digital, Madri, 2004. Disponível em: <http:// www.minotaurodigital.net/textos.asp? art $=84 \&$ seccion $=$ Arte $\&$ subseccion $=$ articulos2004? $>$. Acesso em: 26 maio 2009.

FONSECA, C. A poesia do acaso: na transversal da cidade. São Paulo: T. A. Queiroz, 1982.

[SYN]THESIS, Rio de Janeiro, vol.7, nº 2, 2014, p. 217 - 229 
GANZ, N. O mundo do grafite: Arte urbana dos cinco continentes. Tradução de Rogério Bettoni. São Paulo: Martins Fontes, 2008.

GARRAFFONI, R. S. Contribuições da epigrafia para o estudo do cotidiano dos gladiadores romanos no início do principado. Revista História, São Paulo, v. 24, n.1, 2005.

GINZBURG, C. A micro-história e outros ensaios. Tradução de Antônio Narino. Rio de Janeiro: Bertrand/Difel, 1991.

GITAHY, C. O que é graffiti? São Paulo: Brasiliense, 1999.

GONÇALVES, A. X. T. A pedagogia do spray: o que faz o grafiteiro. 2006. Tese (Doutorado em Educação) - Pontifícia Universidade Católica, Rio de Janeiro.

GRAFFITI, das ruas para a galeria. A Rede: Tecnologia para inclusão social, ano 4, n. 36, maio 2008. Disponível em: <http:/ /www.arede.inf.br/inclusao/edicao-no36-maio2008/1379>. Acesso em: 20 jun. 2010.

GREENBAUM, H.; RUBINSTEIN, D. The origin of spray paint. The New York Times. November 4, 2011. Disponível em: <http://www.nytimes.com/2011/11/06/magazine/who-madespray-paint.html?_r=0>Acesso em: 13 abr. 2013.

GUELMAN, L. C. Brasil: Tempo de Gentileza. Niterói: EDUFF, 2000.

HISTÓRIA do Hip Hop. Portal de Campo Grande, Rio de Janeiro. Disponível em: <http://www.pcg.com.br/eblack/ 01.htm>. Acesso em: 01dez. 2006.

LEÃO, T. O Fanzine. O Globo, Rio de Janeiro, 16 nov. 2001. Segundo caderno, p. 4-5.

KNAUSS, P. Arte Pública e Direito à Cidade: o encontro da arte com as favelas no Rio de Janeiro contemporâneo. Tempo e Argumento - Revista do Programa de Pós-Graduação em História da UDESC, Florianópolis, v. 1, n. 1, p. 17-29, jan./ jun. 2009.

. O desafio de fazer história com imagens: arte e cultura visual. ArtCultura, Uberlândia, v.8, n.12, jan./jun. 2006. Disponível em: <http://www.artcultura.ppghis.inhis.ufu.br/ viewarticle.php?id=130>. Acesso em: 10 abr. 2009 .

. Grafite urbano contemporâneo. In: TORRES, S. (Org.). Raízes e rumos: perspectivas interdisciplinares em estudos americanos. Rio de Janeiro: 7 Letras, 2001, p. 334-353.

. Introdução. In: KNAUSS, P. (Coord.). Sorriso da cidade: imagens urbanas e história política de Niterói. Niterói: Fundação de Arte de Niterói, 2003, p. 9-22.

LEAL, A. L. P. Um olhar obre a cena do graffiti no Rio de Janeiro. Dissertação (Mestrado em Antropologia)Universidade Federal Fluminense, Niterói: UFF, 2009

LEVY, D. Peintre et graffiti artiste. 2005. Disponível em: <http:/ /www.col.fr/article-843.html>. Acesso em: 21 nov. 2007.

LEY, D.; CYBRIWSKY, R. Urban graffiti as territorial markers. Annals of The Association of American Geographers, v. 64, n. 4, December 1974, p. 491-505.
MANCO, T.; NEELON, C. Graffiti Brasil. London: Thames \& Hudson, 2005.

MARCONDE, J. L. A arte da intervenção. A Rede: Tecnologia para inclusão social, ano 1, n. 9, dez. 2005, p. 44-46.

MARCONOT, Jean-Marie. Le langage des murs: du graffe au graffiti. Montpellier: Presses du Languedoc, 1995.

McCORMICK, C.; SCHILLER, M.; e SCHILLER, S. Trespass: História da arte urbana não encomendada. Trad. de Luiz Manuel Gameiro Romero e Rita Simões. Barcelona: TASCHEN, 2010.

MEDEIROS, D. (Boleta). (Org.). Ttsss... A grande arte da pixação em São Paulo, Brasil. São Paulo: Editora do Bispo. [200-?].

NEELON, C. Rustoleum's new cap and the demise of american spray paint. September 28, 2010. Disponível em: <http:// imprint.printmag.com/caleb-neelon/american-spraypaint-andamerican-competitiveness/>. Acesso em: 11 abr. 2013.

ORLANDI, E. P. Cidade dos sentidos. Campinas, São Paulo: Pontes, 2004.

PAIS, J. M.; BLASS, L. M. Tribos Urbanas: produção artística e identidades. Lisboa: Imprensa de Ciências Sociais, 2004, p. 15.

PALMER, R. Street art Chile. London: Eigthbooks, 2008.

POATO, S. (Org.). O graffiti na cidade de São Paulo e sua vertente no Brasil: estéticas e estilos. São Paulo: USP, 2006.

PROSSER, E. S. Arte de rua, caricatura e gravura: crítica e política. In: FÓRUM DE PESQUISA CIENTÍFICA EM ARTES, 4.; 2006, Curitiba. Anais... Curitiba: Escola de Música e Belas Artes do Paraná, 2006.

RAMOS, C. M. A. Grafite, pichação \& cia. São Paulo: Annablume, 1994.

RAP BRASIL CULTURA DE RUA. São Paulo: Escala, 2000, ano 1, n. 2 , n. 3 , n. 5 , n. 6 , n. 31 .

REVISTA RAP BRASIL ESPECIAL. Graffiti. São Paulo: Escala. 2006, n'. 30 e nº. 31 .

SILVA-E-SILVA, W. da. Graffitis em múltiplas facetas: definições e leituras iconográficas. São Paulo: Annablume, 2011.

A trajetória do graffiti mundial. Bahia: Revista Ohun, ano 4, n. 4, Bahia, 2008. Disponível em: <http:// www.revistaohun.ufba.br>. Acesso em: 10 jul. 2008.

STEWART, J. Graffiti kings: New York city mass transit art of the 1970s. New York: Abrams, 2009.

VAZ, T. Graffiti, na parede da galeria. A Rede: Tecnologia para inclusão social, ano 4, n. 36, maio 2008, p. 38-40. 